\title{
Polarograms of Bismuth, Antimony and Arsenic in Sulfuric Acid Solution Containing Manganese (II) Sulfate and Methylene Blue*
}

\author{
Masayasu Tsuiki**
}

In the previous paper ${ }^{1)}$, polarograms of bismuth, antimony and arsenic were studied in sulfuric acid solutions containing manganese (II) sulfate and gelatin, in order to determine these three elements in lead metal simultaneously. It was found that the polarograms of bismuth and antimony were welldefined, and that the second wave of arsenic was fairly well-defined when the concentration of arsenic was lower than 0.4 millimolar, while the first wave of arsenic was ill-defined and, at the higher concentrations, the wave heights of both waves were reduced.

In the later investigations which were made with the same procedure as before, however, it was observed that such anomalies of arsenic waves can be completely eliminated by the use of methylene blue instead of gelatin. In the present paper, the effects of the concentrations of gelatin, methylene blue, sulfuric acid, manganese (II) sulfate and hydrochloric acid on the polarograms of bismuth, antimony, and arsenic were studied. The simultaneous polarograms of the three elements were clearly obtained, when the concentration of each element was between 0.2 and $5 \mathrm{mg}$ per $100 \mathrm{~m} l$, in the solution containing $1 \mathrm{~N}$ sulfuric acid, $1 \mathrm{M}$ manganese (II) sulfate, $0.1 \mathrm{~N}$ hydrochloric acid, and $8 \times 10^{-4} \%$ methylene blue.

The results obtained are as follows.

\section{Effect of Maximum Suppressors on the arsenic waves}

The effects of gelatin and methylene blue on the arsenic waves were investigated in $1 N$ sulfuric acid solution containing $1 \mathrm{M}$ manganese (II) sulfate. Gelatin gave unsatisfactory results because of a marked reduction in wave height with the increase of the concentration of gelatin (Fig. 1) or arsenous acid (higher than about 0.4 millimollar) (Fig. 2). In addition to this reduction of wave height shown in Fig. 2, the ratio of the height of the first wave to that of the second one changed (Fig. 3) and the potential of the first wave shifted toward more positive potentials (Table 1) with the increasing concentration of sulfuric acid. These results indicate that the two waves of arsenic are not completely separated. Methylene blue gave no anomaly and, thus, was a satisfactory maximum suppressor as shown in Figs. 4 6, that is, it made both arsenic waves well-defined at concentrations up to at least 1 millimolar of arsenous acid.

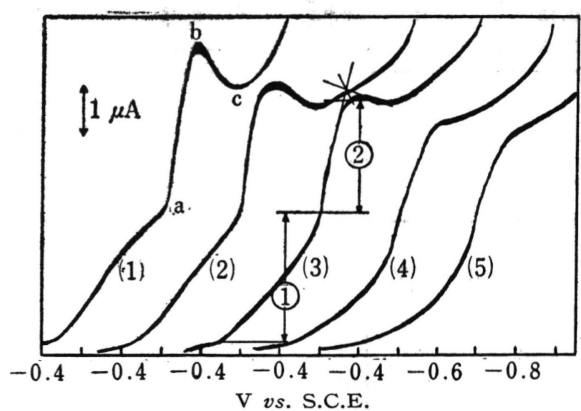

In $1 N$ sulfuric acid solutions containning $1 \mathrm{M}$ manganese (II) sulfate and (1) 0 , (2) 0.004 , (3) 0.008 , (4) 0.010 , and (5) $0.012 \%$ gelatin.

Fig. 1 Polarograms of $0.4 \mathrm{~m} M$ arsenic (III)

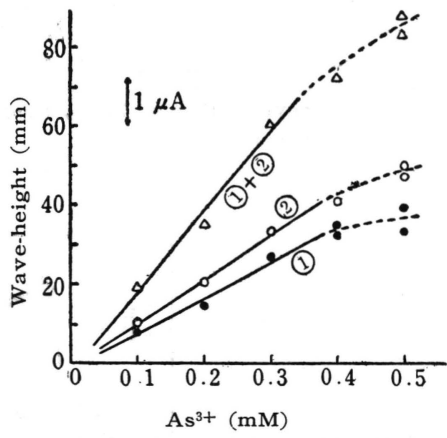

In the solutions containing $1 \mathrm{~N}$ sulfuric acid, $1 M$ manganese (II) sulfate, and $0.01 \%$ gelatin.

Fig. 2 Relation between the amount of arsenic (III) and wave-heights

* Simultaneous Determination of Bismuth, Antimony and Arsenic in Lead Metal by Polarography (Part 2 )

** Department of Industrial Chemistry, Faculty of Engineering, Gifu Univdrsity, Gifu,

The original written in Japanese can be seen in J. Electrochem. Soc. Japan 28, 687 (1960). 


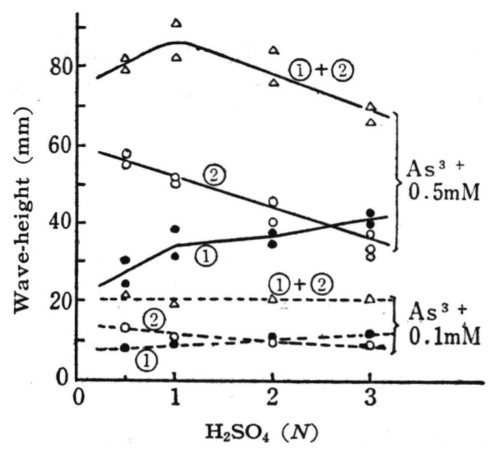

In $1 M$ manganese (II) sulfate solutions containing $0.01 \%$ gelatin and $0.5 \mathrm{mM}$ or $0.1 \mathrm{~m} M$ arsenic (III).

Fig. 3 Relation between the amount of sulfuric acid and arsenic wave-heights

Table 1 Influences of the Concentrations of Supporting Electrolytes on the Half-Wave Potentials of Bismuth, Antimony, and Arsenic

\begin{tabular}{|c|c|c|c|c|c|c|}
\hline \multicolumn{3}{|c|}{ Supporting electrolyte* } & \multicolumn{4}{|c|}{ Half-wave potential (V vs S.C.E.) } \\
\hline \multirow{2}{*}{$\mathrm{H}_{2} \mathrm{SO}_{4}(N)$} & \multirow{2}{*}{$\mathrm{MnSO}_{4}(M)$} & \multirow{2}{*}{$\mathrm{HCl}(N)$} & \multirow{2}{*}{$\begin{array}{c}\mathrm{Bi}^{3+} \\
(0.12 \mathrm{mM})\end{array}$} & \multirow{2}{*}{$\begin{array}{c}\mathrm{Sb}^{3+} \\
(0.12 \mathrm{mM})\end{array}$} & \multicolumn{2}{|c|}{$\mathrm{As}^{3+}(0.2 \mathrm{~m} M)$} \\
\hline & & & & & (1)** & (2) \\
\hline- & 1.0 & 0.1 & -0.03 & -0.18 & -0.51 & -0.73 \\
\hline 0.5 & 1.0 & 0.1 & -0.04 & -0.16 & -0.46 & -0.69 \\
\hline 1.0 & 1.0 & 0.1 & -0.04 & -0.15 & -0.44 & -0.67 \\
\hline 1.5 & 1.0 & 0.1 & -0.05 & -0.15 & -0.42 & -0.67 \\
\hline 2.0 & 1.0 & 0.1 & -0.05 & -0.14 & -0.40 & -0.65 \\
\hline 3.0 & 1.0 & 0.1 & -0.08 & -0.16 & -0.38 & -0.66 \\
\hline 4.0 & 1.0 & 0.1 & -0.08 & -0.16 & -0.38 & -0.66 \\
\hline 1.0 & 0.5 & 0.1 & -0.05 & -0.16 & -0.46 & -0.68 \\
\hline 1.0 & 1.0 & 0.1 & -0.04 & -0.15 & -0.44 & -0.67 \\
\hline 1.0 & 1.5 & 0.1 & -0.05 & -0.16 & -0.42 & -0.68 \\
\hline 1.0 & 1.0 & - & -0.03 & -0.15 & -0.44 & -0.67 \\
\hline 1.0 & 1.0 & 0.05 & -0.03 & -0.14 & -0.44 & -0.67 \\
\hline 1.0 & 1.0 & 0.1 & -0.04 & -0.15 & -0.44 & -0.67 \\
\hline 1.0 & 1.0 & 0.2 & -0.06 & -0.15 & -0.43 & -0.67 \\
\hline- & 1.0 & 0.5 & -0.05 & -0.15 & -0.47 & -0.68 \\
\hline- & 1.0 & 1.0 & -0.09 & -0.16 & -0.42 & -0.67 \\
\hline- & 1.0 & 2.0 & \multicolumn{2}{|c|}{-0.15} & -0.36 & -0.65 \\
\hline- & 1.0 & 3.0 & \multicolumn{2}{|c|}{-0.18} & -0.30 & -0.64 \\
\hline
\end{tabular}

* Methylene blue $8 \times 10^{-4} \%$, temp. $25^{\circ} \mathrm{C}$

** Shown in Fig. 9

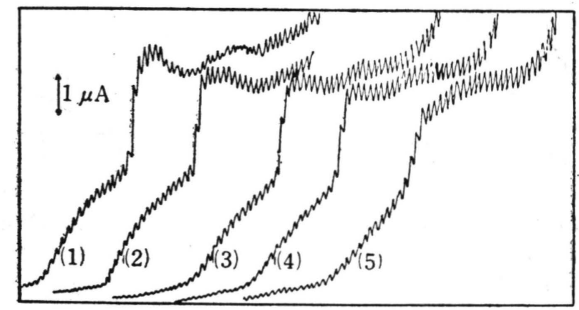

In $1 N$ sulfuric acid solutions containing $1 M$ manganese (II) sulfate and (1) 0.0 , (2) 0.00004 , (3) 0.0006 , (4) 0.0010 , and (5) $0.0040 \%$ methylene blue.

Fig. 4 Polarograms of $0.3 \mathrm{~m} M$ arsenic (III) 


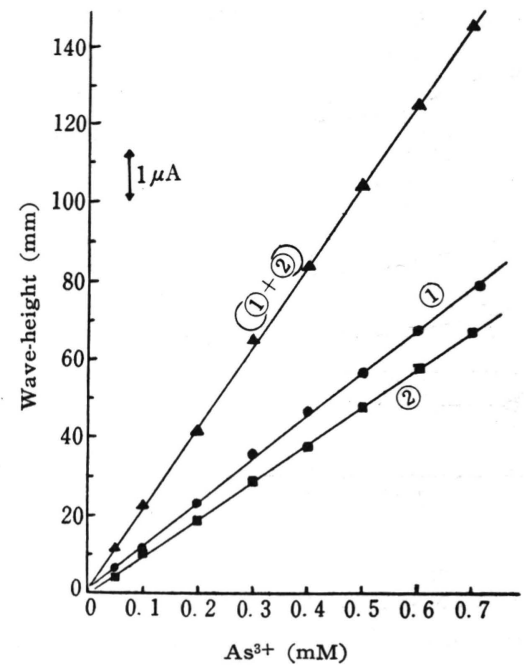

In the solutions containing $1 N$ sulfuric acid, $1 M$ manganese (II) sulfate, and $8 \times 10^{-4} \%$ methylene blue.

Fig. 5 Relation between the amount of arsenic (III) and wave-heights

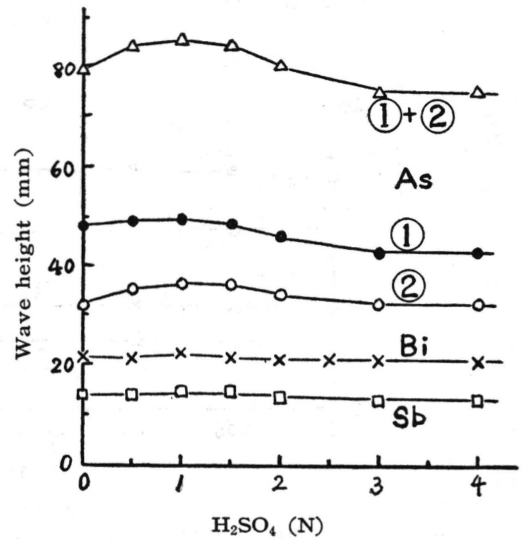

Of $0.4 \mathrm{mM}$ arsenic (III), $0.24 \mathrm{~m} M$ bismuth (III), and $0.25 \mathrm{~m} M$ antimony (III) in $1 M$ manganese (II) sulfate solutions containing $0.1 \mathrm{~N}$ hydrochloric acid and $8 \times 10^{-4} \%$ methylene blue,

Fig. 6 Relation between the amount of sulfuric acid and wave-height

\section{Effects of the Concentration of Sulfuric Acid}

With increasing the sulfuric acid concentration, the half-wave potential of bismuth shifted to more negative potentials and that of the first arsenic wave to more positive potentials, both closing to that of antimony (Table 1). The wave heights of bismuth and antimony were nearly constant and those of the two arsenic waves were nearly the same though they were somewhat high at about $1 \mathrm{~N}$ sulfuric acid (Fig. 6). These facts are considered to be resulted from the two arsenic waves being completely separated in this condition; the difference in the two half-wave potentials is about $0.22 \mathrm{~V}$, while that obtained with gelatin, $0.15 \mathrm{~V}$. From these results, it was concluded that $1 \mathrm{~N}$ sulfuric acid is most suitable for the determination.

\section{Effects of Manganese (II) Sulfate}

With increasing the manganese (II) sulfate concentration, the potential of the first arsenic wave

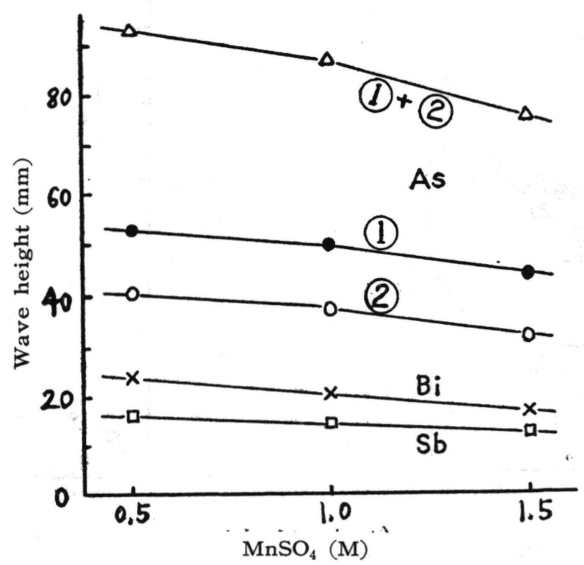

$0.4 \mathrm{mM}$ arsenic (III), $0.24 \mathrm{mM}$ bismuth (III), and $0.25 \mathrm{mM}$ antimony (III) in $1 \mathrm{~N}$ sulfuric acid solutions containing $0.1 N$ hydrochloric acid and $8 \times 10^{-4} \%$ methylene blue.

Fig. 7 Relation between the amount of manganese (III) sulfate and wave-heights 


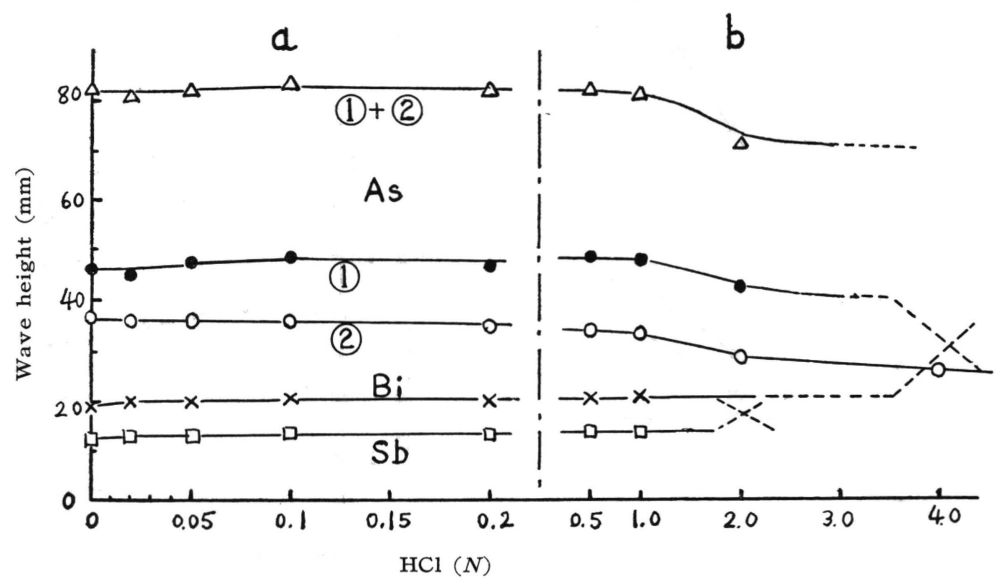

$0.4 \mathrm{~m} M$ arsenic (III), $0.24 \mathrm{~m} M$ bismuth (III), and $0.25 \mathrm{~m} M$ antimony (III) in $1 M$ manganese (II) sulfate solutions containing $8 \times 10^{-4} \%$ methylene blue and (a) $1.0 \mathrm{~N}$ and (b) $0.0 \mathrm{~N}$ sulfuric acid.

Fig. 8 Relation between the amount of hydrochloric acid wave-heights

shifted to more positive potentials (Table 1 ) and all waves of the three elements decreased in height (Fig. 7). As the concentration of manganese (II) sulfate which is introduced upon the chemical separation of the three elements from lead by means of co-precipitation with manganese di-oxide (JIS H 1121-1956) is less than 0.05 molar, the most suitable concentration of manganese (II) sulfate to be added is about one mol per liter.

\section{Effects of Hydrochloric Acid}

Hydrochloric acid, which is to be added to the solution at the last procedure of separating the three elements from lead, was found to give almost no effect on the heights of all waves unless its concentration exceeds $1 \mathrm{~N}$. At higher concentrations, however, the potential of bismuth shifted to more negative potentials, that of the first arsenic wave to more positive potentials and both of them coincided with that of the antimony wave at concentrations about $2 N$ and $4 N$ hydrochloric acids respectively

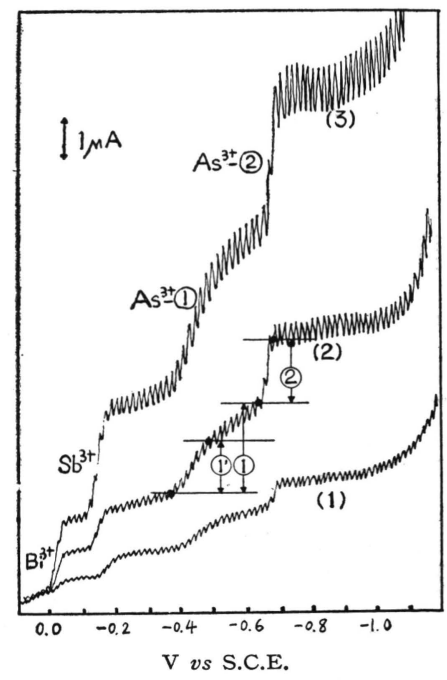

(1) 0.05, (2) 0.14, (3) $0.24 \mathrm{~m} M$ bismuth (III), (1) 0.08 ,

(2) 0.2 , (3) $0.4 \mathrm{mM}$ antimony (III) land (1) 0.1 , (2) 0.25 ,

(3) $0.5 \mathrm{mM}$ arsenic (III) in the solutions comprising $1 \mathrm{~N}$ sulfuric acid, $1 \mathrm{M}$ manganese (II) sulfate, $0.1 \mathrm{~N}$ hydrochloric acid, and $8 \times 10^{-4} \%$ methylene blue.

Fig. 9 Simultanious polarograms

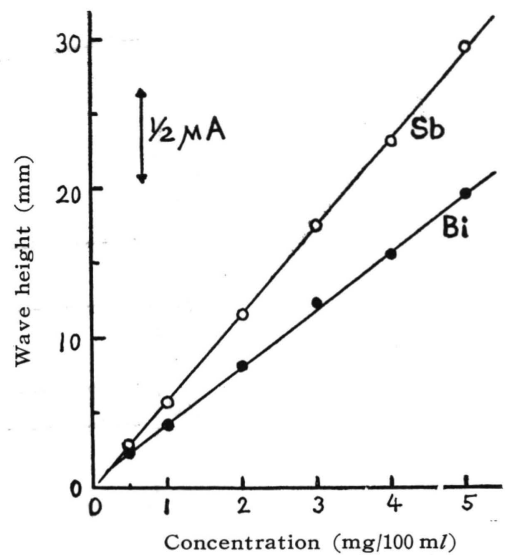

In the solutions comprising $1 N$ sulfuric acid, $1 M$ manganese (II) sulfate, $0.1 \mathrm{~N}$ hydrochloric acid, and $8 \times 10^{-4} \%$ methylene blue.

Fig. 10 Relation between wave-heights and the amount of bismuth or antimony 
(Fig. 8, Table 1). Since the concentration of the hydrochloric acid introduced is about $0.1 \mathrm{~N}$, no difficulty is found in the quantitative determination.

\section{Simultaneous Determination of Bismuth, Antimony, and Arsenic}

In the supporting electrolyte containing $1 N$ sulfuric acid, $1 M$ manganese (II) sulfate, $0.1 N$ hydrochloric acid and $8 \times 10^{-4} \%$ methylene blue, well-defined simultaneous polarograms of the three elements were obtained at the concentration of each element between 0.2 and $5 \mathrm{mg}$ per $100 \mathrm{~m} l$. The potentials and the wave heights of these polarograms were satisfactory for the determination (Figs. 9,5 and 10). The half-wave potentials of bismuth, antimony, and the first and the second wave of arsenic were about $-0.04,-0.15,-0.44$ and $-0.67 \mathrm{~V}$ vs S.C.E., respectively.

(Received Apr. 26, 1960)

\section{Literature :}

1) M. Tsuiki and T. Kawase, Research Repts. Fac. Eng. Gifu Univ. 10, 26 (1960). 